\title{
The Effect of An Educational Intervention on Teachers' Knowledge, Attitude, and Behavior regarding Attention Deficit Hyperactivity Disorder (ADHD)
}

\section{Maede hossennia}

Isfahan University of Medical Sciences

Maryam Amidi Mazaheri ( $\sim$ maryamamidi@hlth.mui.ac.ir)

Isfahan University of Medical Sciences School of Public Health https://orcid.org/0000-0002-0169-5997

\section{Zahra Heidari}

Isfahan University of Medical Sciences

\section{Research}

Keywords: ADHD, Teachers, Knowledge, Attitude, Iran, Intervention

Posted Date: August 24th, 2020

DOI: https://doi.org/10.21203/rs.3.rs-56749/v1

License: (c) (1) This work is licensed under a Creative Commons Attribution 4.0 International License. Read Full License 


\section{Abstract}

Background: this study evaluated the effect of an educational intervention for increasing elementary school teachers' ADHD knowledge, attitudes, and behavior.

Method: Teachers from 12 schools who had at least one student with a definitive diagnosis of ADHD participated in the study and were allocated into either an intervention $(n=31)$ or control group $(n=27)$. Teachers' ADHD knowledge, Attitude, and Behavior were assessed before and after intervention. Six-session participatory intervention were provided only for the intervention group.

Results: Two mounts after the intervention, the intervention group scored significantly higher on all three outcomes $(P \leq 0.001)$.

Conclusion: The educational intervention significantly improved teachers', knowledge, attitudes as well as their behaviors and strategies to manage children with ADHD. It is recommended that this program will incorporate into in-service training courses for primary school teachers as a means of facilitating teaching and managing children with ADHD in class.

Trial registration: The study was approved by the by the Research Deputy of Isfahan University of Medical Sciences. In addition, The Ethical Committee of Isfahan University of Medical Sciences approved the study proposal. (ID code: IR.MUI.RESEARCH.REC.1398.297). The required permission from Education Department of Isfahan City was attained. Participation in the study was voluntary. Before taking part in the study, selected teachers provided written consent also study goals were described to them.

\section{Introduction}

Attention deficit disorder with hyperactivity (ADHD) is an important issue associated with the fields of psychiatry and education. Defined as a neurodevelopmental disorder, this condition progresses with hyperactivity, lack of attention, and impulsivity $(1,2)$. Based on DSM-5 (Diagnostic and Statistical Manual of Mental Disorders, 5th edition) hyperactivity/impulsivity and/or lack of attention in adolescents and children requires the common observation of at least six symptoms in multiple settings (at least two different social settings). Also, the symptoms must last in an unsuited style with developmental level for at least six months, ADHD symptoms must begin before the age of 12 , so that a diagnosis can be made (3).

Numerous studies around the world have indicated that the prevalence of ADHD has significantly increased over the past two decades (4-7). According to a population-based survey among 30,532 children and adolescents between 6 and 18 years in Iran, the prevalence of ADHD was $4 \%$, with more prevalence among boys $(5.2 \%$ vs. $2.7 \%)(8)$.

ADHD symptoms adversely impact the cognitive, emotional, behavioral, social, and academic functioning of the children (7). Various studies have reported that most of the children with ADHD experience different behavioral and social problems at home and school (9); among these problems, mention can be made of anxiety disorder (10), the likelihood of being rejected by friends and peers (11), the issues related to the 
evolution of identity, and social communication (12). This disorder not only negatively affects the different aspects of individual functioning, but also influences the members of the family and society (13).

Despite the fact that early diagnosis and stable treatment are highly critical, literature search indicates that it is at least not until children start their education that ADHD is diagnosed because the parents and teachers do not have sufficient knowledge as to the serious consequences of this disorder (14). Therefore, elementary school teachers play a critical role in the early diagnosis and effective management of ADHD (15).

An elementary school teacher is most often the first to notice hyperactivity or inattentive behaviors in the classroom, and they should be able to manage such students and do the right thing such as make a referral for accurate assessment for ADHD (16). Elementary school teachers play an important role in the assessment of children's behavioral and academic problems owing to their extensive interaction with children in a variety of unstructured and structured settings (17). Furthermore, they play a crucial part in the implementation, support, and assessment of recommended treatment plans for affected children (15). These teachers also make recommendations, inappropriate or appropriate, concerning ADHD to the parents who tend to follow such recommendations (18).

Teachers face numerous challenges when ADHD children are present in class along their peers and friends $(5,19,20)$. Therefore, they need adequate knowledge regarding the problems and special needs of these children, and they have to plan effective behavior management strategies in dealing with them (17). Nonetheless, findings from previous research show that elementary school teachers may be inadequately prepared to effectively support children with ADHD; this is due to their little knowledge about this disorder as well as the negative attitudes and misconceptions towards affected children that is the result of limited training $(15,20-22)$.

The results of a study by Amidi showed that teachers' knowledge regarding the ADHD symptoms was higher than their knowledge of the etiology of ADHD as well as the treatment methods and ADHD consequences. In addition, some of the teachers had misconceptions about this disorder, going so far as to punish these students (13).

Evidence-based research indicates that teachers with prior ADHD training have significantly higher knowledge and fewer negative attitudes and misconceptions towards affected children (22).

It is important to improve teacher's awareness and understanding and modify their negative attitudes towards ADHD; accordingly, this study was designed to assess the effect of an ADHD educational intervention on the knowledge, attitudes, and behavior of elementary school teachers in Isfahan, Iran. To the authors' knowledge, only a small number of studies have focused on evaluating the effect of teacher's education on ADHD in Iran. The current study aimed to respond to and examine the following question and hypothesis:

Research Question: Can educational intervention increase teachers' knowledge and enhance their attitudes and behavior in regard to ADHD?

It was hypothesized that the intervention would increase teachers' ADHD knowledge, attitudes, and behavior. 


\section{Methods}

\section{Design}

This quasi-experimental study with a randomized control group was conducted in Isfahan province of Iran, in the autumn of 2019. Fifty-four primary school teachers were assigned to an intervention group $(n=27)$ and a control group $(n=27)$.

\section{Participants}

In this research, we used a multi-stage sampling method, where initially, one of the five Education Offices in Isfahan (Office 3) was randomly selected; afterwards, 12 elementary schools were randomly chosen from a list of elementary schools in that area (six public primary and six private schools). Three public and three private primary schools were randomly assigned as the intervention group and three public and three private primary schools were considered as the control group.

In the selected schools of both groups, all students with a definitive diagnosis of ADHD were identified based on their medical records, and their teachers were invited to participate in the study. Interested teachers were assessed for inclusion criteria (71 teachers). Ultimately, based on the inclusion criteria, eligible teachers (58 teachers) participated in the study as either intervention $(n=31)$ or control $(n=27)$ groups.

To participate in this study, teachers were required to meet the following inclusion criteria: (a) willingness to participate and (b) having at least two years of work experience as a schoolteacher. They were excluded from the study if they did not attend more than one session of training.

\section{Procedure}

The study was approved by the by the Research Deputy of Isfahan University of Medical Sciences (397796). In addition, The Ethics Committee of Isfahan University of Medical Sciences approved the study proposal (ID code: IR.MUI.RESEARCH.REC.1398.297). The required permission was obtained from the Education Department of Isfahan City. Participation was voluntary in the study, and prior to entering the study, the selected teachers provided written consent, and the study goals were delineated for them. Eligible teachers in the selected schools (of both groups) attended a single 30-minute assessment session to complete the assessment tools before the intervention. The training sessions were provided only for the teachers in the intervention group. Following two months, participants in both groups once again completed the questionnaires.

\section{Measures}

A self-reported questionnaire, developed by the researchers, was used for data collection. This questionnaire was developed based on a literature review to evaluate teachers' knowledge, attitudes, and behaviors to support children with $\operatorname{ADHD}(2,9,15,16,20,22)$.

An expert panel, selected based on their qualifications and experience in health education, psychology, and $A D H D$, specified the face validity and content validity of the questionnaires. 
The opinions of the experts resulted in minor modifications in the wording of several items. In addition, the expert panel indicated that the means CVI (item relevance) was acceptable for the questionnaires and their subscales. Finally, the questionnaire was tested in a classroom setting with 10 elementary school teachers, where they assessed the difficulty and understandability of the questionnaire. This tool had two main parts:

1- The demographic information checklist, including age, years of experience as a primary school teacher, education level, marital status, and prior participation in training workshops on ADHD.

2- The Teacher's ADHD Knowledge, Attitude, and Behavior Scale. This scale comprises 36 items and 3 subscales. Using 12 items, the first subscale measured the teacher's general Knowledge on ADHD. The answers were designated as "true", "false", or "don't know". Correct answers were given '2', incorrect answers were assigned ' 0 ', and don't know responses were considered as ' 1 '. Examples of these items are as follows: attention deficit disorder only improves with medication, or children diagnosed with ADHD usually behave thoughtlessly. The correct answers were summed into a knowledge score where higher scores indicated a better knowledge of ADHD (range 0-36, $a=0.89$ ).

Using 12 items, the second subscale assessed teachers' beliefs and attitudes about ADHD, scored based on a three-point Likert scale (disagree $=1$, no idea $=2$, and agree $=3$ ).

The answers were summed to reach an ADHD attitude score, where higher scores indicated a more positive attitude (range $12-36, a=0.94$ ). Here are some example items: I think it takes more time for students diagnosed with ADHD to do their classroom exercises or I think students diagnosed with ADHD need more support than their peers.

The third subscale consisted of 12 items to investigate teachers' behaviors and strategies for managing ADHD children in the classroom. In the beginning of the subscale, the teachers were given a short scenario displaying the typical behavioral problems of an ADHD student in regular classrooms. Each item asked them questions on the strategies commonly recommended for use with ADHD students. For instance, reinforcement, organizing classroom/curriculum, negative consequences, emotional support, and planned ignoring. Teachers indicated their responses to items using a four-point Likert scale ranging from 1 (never) to 4 (most of the time). The answers were summed to generate a behavior score with higher scores indicating more support and better behaviors and strategies for managing children with ADHD. (range 12-48, $a=0.95$ ).

\section{Intervention:}

Based on an extensive review of relevant literature, the intervention was developed as a six-session training only for the teachers in the intervention group. The Classroom Accommodations for Children with ADHD (23) was selected by researchers as an intervention design framework.

Skilled and trained educators in the field of ADHD delivered conducted every session. Every session, presented in lecture format, ran lasted for 45 minutes to 1 hour (including a 10-min break) and it was presented in lecture format. Additionally, role-playing and, and active participation in-group discussion were used employed as supportive activities in the intervention. The participants were encouraged to share their comments and questions during the presentation. In each session, two trained facilitators encouraged 
teachers to explore, discuss, and practice learned managing strategies. Via in-group work, teachers were provided with a good opportunity to hear others' experiences and share similar teaching and managing experiences with each other. They were able to modify their approaches to different classroom situations and receive confirmation and support for their individual practices to become more confident and effective. The contents of the sessions are as follows:

Session 1: defining ADHD: the symptoms and diagnosis, ADHD etiology and epidemiology, short-term and long-term consequences of $\mathrm{ADHD}$, manifestations in the classroom, and common treatment strategies.

\section{Session 2}

the main principles to be considered in regard to the planning and management of programs for ADHD students.

\section{Session 3}

the main behavior strategies that must be taken used by the teacher to increase incentives, for example, increase increasing praise, approval, and appreciation of student's good behavior and work performance.

\section{Session 4}

self-awareness training to display students' work productivity on a daily chart or graph on the public.

\section{Session 5}

fundamental methods and measures for making rules and time clearer for ADHD students.

\section{Session 6}

The possible punishment methods in case of necessity. Moreover, a summary of medications used for ADHD treatment was provided to point out the effect of probably side effects such as stomachaches, insomnia, reduced appetite, growth problems, and irritability.

\section{Statistical analysis}

Because the teachers were randomly assigned to two groups, possible differences could still exist. Teachers' age, years of experience, level of education, marital status, and prior training workshops on ADHD and student's sex and school type (private or public) were compared between the intervention and control groups using descriptive statistics, Chi-square test, and independent-sample t-test.

Independent t-tests were applied in both groups to examine the effects of the intervention on knowledge, attitudes, and behaviors before and after the intervention.

Analysis of covariance (ANCOVA) was applied to examine the effect of educational intervention. The postintervention scores were set as the dependent variables and the group (two levels: intervention and control group) was set as a fixed factor; also, pre-intervention scores were set as covariates and controlled for. 
Statistical analyses were performed by the 20th version of the Statistical Package for the Social Sciences (SPSS) for Windows, with $p \leq .05$ as the significance level.

\section{Results}

Of note, 58 subjects participated in the study and completed the baseline measures: 31 teachers in the intervention and 27 teachers in the control group. Table 1 summarizes the demographic characteristics for the intervention and control groups. No statistically significant differences were detected between the intervention and control groups as regards age, years of experience as a primary school teacher, school type (private or public), level of education, marital status, and prior ADHD courses. All of the teachers in the study were women, and most were married. More than half of the teachers in both groups, the study had attended no prior ADHD training.

Seven teachers were excluded from the intervention group because three of them did not attend more than one session of training, and four teachers were not available for the follow-up measures. Similarly, in the control group, 27 teachers filled the baseline measures while 24 teachers were available for the follow-up measures. In the final analysis, 24 teachers were included the intervention, and 24 teachers were assigned to the control group.

As shown in Table 2, at baseline, the scores on knowledge, attitude, and behavior were not significantly different between the two groups. However, two mounts after the intervention, ANCOVA showed that the intervention group scored significantly higher on all three outcomes $(P \leq 0.001)$. Furthermore, the results of the paired t-test showed a significant improvement in the knowledge, attitude, and behavior of the intervention group. However, in the control group, there was no statistically significant pre-to-post improvement in any teacher's measures.

\section{Table 1. Teacher Characteristics}




\begin{tabular}{|c|c|c|c|c|}
\hline Variables & $\begin{array}{l}\text { Intervention group } \\
(n=31)\end{array}$ & $\begin{array}{l}\text { Control group } \\
(n=27)\end{array}$ & $t$ test or $\chi 2$ & $\mathbf{p}$ \\
\hline Age, mean (SD) & $45.50(6.45)$ & $44.54(5.54)$ & 0.55 & 0.552 \\
\hline years of teaching, mean (SD) & 15.33(9.68) & $13.42(10.10)$ & 0.67 & 0.869 \\
\hline \multicolumn{5}{|l|}{ Type of school No (\%) } \\
\hline Public & $14(45.1)$ & $12(44.4)$ & \multirow[t]{2}{*}{1} & \multirow[t]{2}{*}{0.54} \\
\hline Private & $17(54.9)$ & $15(55.6)$ & & \\
\hline \multicolumn{5}{|l|}{ Education No (\%) } \\
\hline Associate's degree & $8(25.8)$ & $6(22.2)$ & \multirow[t]{3}{*}{1} & \multirow[t]{3}{*}{0.62} \\
\hline Bachelor's degree & $14(45.1)$ & 14(51.9) & & \\
\hline Master's degree & $9(29.1)$ & $7(25.9)$ & & \\
\hline \multicolumn{5}{|l|}{ Marital status No (\%) } \\
\hline Single & $2(6.5)$ & 1(3.7) & \multirow[t]{2}{*}{1} & \multirow[t]{2}{*}{0.59} \\
\hline Married & $29(93.5)$ & $26(96.3)$ & & \\
\hline \multicolumn{5}{|c|}{ Previous training about ADHD No (\%) } \\
\hline Yes & $13(41.9)$ & 11(40.7) & \multirow[t]{2}{*}{1} & \multirow[t]{2}{*}{0.31} \\
\hline No & $18(58.1)$ & $16(59.3)$ & & \\
\hline
\end{tabular}

As shown in Table 2, at baseline, the scores on knowledge, attitude as well as behavior were not significantly different between the two groups. However, two mounts after the intervention, ANCOVA showed that the intervention group scored significantly higher on all three outcomes $(P \leq 0.001)$. The results of the paired $t-$ test showed a significant improvement in knowledge, attitude as well as behavior in the intervention group. However, in the control group, there was no statistically significant pre-to-post improvement on any teacher's measures. 
Table 2

Mean Scores and Standard Deviations Over Time for the Two Groups (Intervention vs. Control).

\begin{tabular}{|c|c|c|c|c|c|c|c|c|c|}
\hline \multirow[t]{2}{*}{ Variable } & \multicolumn{4}{|c|}{ Intervention group $(n=24)$} & \multicolumn{5}{|c|}{ Control group $(n=24)$} \\
\hline & $\begin{array}{l}\text { Baseline } \\
\text { M } \\
\text { (SD) }\end{array}$ & $\begin{array}{l}\text { End } \\
M \\
\text { (SD) }\end{array}$ & $\begin{array}{l}\text { Change } \\
M \\
\text { (SD) }\end{array}$ & $\begin{array}{l}\text { P- } \\
\text { value }^{a}\end{array}$ & $\begin{array}{l}\text { Baseline } \\
\text { M } \\
\text { (SD) }\end{array}$ & $\begin{array}{l}\text { End } \\
M \\
\text { (SD) }\end{array}$ & $\begin{array}{l}\text { Change } \\
M \\
\text { (SD) }\end{array}$ & $\begin{array}{l}\text { P- } \\
\text { value }^{a}\end{array}$ & $\begin{array}{l}\text { P- } \\
\text { value }^{\text {b }}\end{array}$ \\
\hline knowledge & $\begin{array}{l}26.45 \\
(6.10)\end{array}$ & $\begin{array}{l}34.45 \\
(6.99)\end{array}$ & $\begin{array}{l}8 \\
(9.17)\end{array}$ & $<_{0.001}$ & $\begin{array}{l}26.22 \\
(6.97)\end{array}$ & $\begin{array}{l}27.04 \\
(7.26)\end{array}$ & $\begin{array}{l}0.41 \\
(1.31)\end{array}$ & 0.135 & $\begin{array}{l}<.001 \\
0.01\end{array}$ \\
\hline Attitude & $\begin{array}{l}22.79 \\
(8.52)\end{array}$ & $\begin{array}{l}31.50 \\
(6.10)\end{array}$ & $\begin{array}{l}8.70 \\
(7.34)\end{array}$ & $<_{0.001}$ & $\begin{array}{l}25.12 \\
(7.45)\end{array}$ & $\begin{array}{l}25.20 \\
(7.39)\end{array}$ & $\begin{array}{l}0.08 \\
(1.41)\end{array}$ & 0.775 & $\dot{0}_{0.001}$ \\
\hline behavior & $\begin{array}{l}25.20 \\
(7.36)\end{array}$ & $\begin{array}{l}36.58 \\
(7.58)\end{array}$ & $\begin{array}{l}11.37 \\
(6.90)\end{array}$ & $\begin{array}{l}<.001 \\
0.00\end{array}$ & $\begin{array}{l}24.33 \\
(6.20)\end{array}$ & $\begin{array}{l}24.04 \\
(6.34)\end{array}$ & $\begin{array}{l}-0.29 \\
(0.69)\end{array}$ & 0.051 & $\begin{array}{l}<.001 \\
0\end{array}$ \\
\hline \multicolumn{10}{|c|}{ P-value $<0.05$ was significant } \\
\hline \multicolumn{10}{|c|}{ Data reported based on Mean (SD) } \\
\hline
\end{tabular}

\section{Discussion}

The purpose of the current study was to evaluate the effects of a six-session participatory ADHD training program on improving elementary school teachers' ADHD knowledge, attitude, and behavior.

Despite the teachers' busy schedules in both groups, the response rate was desirable. As expected, in the intervention group, the teachers and school principals were welcomed in the program. It is important that the needs of children with ADHD be addressed in educational settings.

As predicted, our results demonstrated that participants in the intervention group had significantly higher ADHD knowledge compared with the control group. This result is corroborated by numerous previous studies; in a study in Nigeria, brief ADHD training using a standard training package was able to increase teacher's ADHD knowledge (15). Similarly, an Australian study revealed that brief professional interventions could be utilized to increase teachers' ADHD knowledge (19). The results of a recently published study in Saudi Arabia showed that teachers' training was effective in promoting teachers' ADHD knowledge (14).

Our results also revealed that two mounts after the intervention, the teachers in the intervention group demonstrated a statistically higher attitude towards children with ADHD. Consistent with our findings, desirable changes in teachers' attitude toward students with ADHD were reported after teacher training in previous studies $(15,16,24)$. 
Contrary to the present study, there was no significant difference between pre/post assessments of teachers' attitudes in a similar study in Saudi Arabia (14).

Researchers reported that teachers' attitudes toward children affected with ADHD might be negative (9). Unaware teachers may describe children with ADHD as less favorable and see their behavior as more disruptive to the classroom (13).

In the present study, teachers were provided with a good opportunity to hear others' experiences and share similar teaching and managing experiences with each other by engaging in-group work. Hence, teacher's improved attitudes towards children with ADHD after educational intervention in this study could be attributed to the increase in teacher's knowledge and their corrected misconceptions about ADHD.

Needless to say, teachers' ADHD knowledge and attitudes influence their behavior in the classroom while working with ADHD students. As we expected, the results showed that after intervention, teachers' classroom behavioral management in the intervention group was significantly improved in contrast to the control group.

Similar to our study, ADHD behavior management strategies were reported to be enhanced after teacher training programs (14).

The improvement in ADHD behavior management strategies could be ascribed to teachers' increased knowledge and self-efficacy. A study in Australia revealed that primary school teachers' ADHD knowledge and self-efficacy increased following the educational intervention (22).

In the present study, participants were encouraged to share their comments and questions during each session. Also, two trained facilitators encouraged them to explore, discuss, and practice learned behaviormanaging strategies. They were able to modify their approaches in different class situations and achieve confirmation and support for their individual practices to become more confident and effective.

As teachers' ADHD knowledge increases, their self- efficacy will improve. As a result, they can become more confident in their abilities to make necessary changes, better control the children, and use less destructive behaviors towards children with ADHD. The relationship between ADHD behavior management strategies and teaching self-efficacy requires further support by accurate measures in future research.

The educational intervention based on "The Classroom Accommodations for Children with ADHD" is conducive to improving teachers' understanding of school-aged children with ADHD and their abilities in addressing attention and disruptive behavior problems of ADHD children in the classroom.

This study encountered a number of limitations. First, all outcome measures relied on self-report questionnaires due to the limited available resources. In addition, masking was not possible, meaning socially appropriate responses might have contributed to the higher scores among the teachers in the intervention group. Future studies should include observational measures of teachers' behavior in addition to self-report. 
Second, the participants were aware of which group they were assigned to. The higher scores in intervention, unlike the control group, might have been a function of their expectation that the educational intervention worked. Future studies should maintain blindness by use of a psychological placebo such as a support group.

Third, the teachers were assigned to the control or intervention group at school level rather than as individuals. The latter would have been ideal but impossible because of the time and resource constraints.

Finally, this study examined only short-term outcomes, hence the fact that the long-term impact of education is uncertain. The intervention's positive long-lasting effects await further support by the long-time follow-up measures in future research.

\section{Conclusion}

This six-session participatory intervention significantly improved teachers', knowledge, attitudes, behaviors, and strategies for managing ADHD children. Due to the adverse effects of ADHD on the academic achievement, well-being, and social interactions of children, it is recommended that this program be incorporate into in-service training courses for primary school teachers as a means of facilitating teaching and managing ADHD children in classrooms.

\section{Abbreviations}

ADHD (Attention Deficit Disorder with Hyperactivity)

DSM-5 (Diagnostic and Statistical Manual of Mental Disorders, 5th edition)

\section{Declarations}

Ethics approval and consent to participate: The study was approved by the by the Research Deputy of Isfahan University of Medical Sciences. In addition, The Ethical Committee of Isfahan University of Medical Sciences approved the study proposal. (ID code: IR.MUI.RESEARCH.REC.1398.297). The required permission from Education Department of Isfahan City was attained. Participation in the study was voluntary. Before taking part in the study, selected teachers provided written consent also study goals were described to them.

\section{Consent for publication: "Not applicable"}

Availability of data and materials: The datasets used and/or analyzed during the current study are available from the corresponding author on reasonable request.

Competing interests: "The authors declare that they have no competing interests"

Funding: The Research Deputy of Isfahan University of Medical Sciences provided the sources for this study. 
Authors' contributions: Maede Hosseinnia and Maryam Amidi Mazaheri performed designing the work. Maede Hosseinnia did acquire the data. Interpreting the data was done by Maede Hosseinnia, Maryam Amidi Mazaheri, Zahra Heidari. Drafting the work/ revising the work critically for intellectual content was performed by Maede Hosseinnia and Maryam Amidi Mazaheri.

\section{Acknowledgements}

The authors like to express their gratitude to all principals and teachers participated in this study.

\section{References}

1. Nuri C, Akçamete GA, Direktör C. A Combined Model Study: The Needs of Parents of Children with Attention Deficit Disorder with Hyperactivity (ADHD) in Parent Education. International Electronic Journal of Elementary Education. 2019;12(1):19-26.

2. Knowledge, attitude and behavior of elementary teachers regarding attention deficit hyperactivity disorder in Isfahan. J Edu Health Promot.9(1):120.

3. Epstein JN, Loren RE. Changes in the definition of ADHD in DSM-5: subtle but important. Neuropsychiatry. 2013;3(5):455.

4. Mahmoodi N, Mousavi R. The effectiveness of Group Interventions based on Parent-child Relationship on Promoting Child-rearing in parents of Children with Attention-Deficit Hyperactivity Disorder, aged 6-11 years. MEDICAL SCIENCE. 2019;23(95):12-8.

5. Adeboye M, Akande T, Osagbemi G, Buhari O, Abdulkadir M, Ojuawo A. Attention Deficit Hyperactivity Disorder in Ilorin: Screening with the Conner's Teachers' Rating Scale. Sierra Leone Journal of Biomedical Research. 2018;10(1):33-41.

6. Safavi P, Ganji F, Bidad A. Prevalence of attention-deficit hyperactivity disorder in students and needs modification of mental health services in Shahrekord, Iran in 2013. Journal of clinical and diagnostic research: JCDR. 2016;10(4):LC25.

7. Yadegari N, Sayehmiri K, Azodi MZ, Sayehmiri F, Modara F. The prevalence of attention deficient hyperactivity disorder among Iranian children: A meta-analysis. Iranian Journal of Psychiatry and Behavioral Sciences. 2018;12(4).

8. Mohammadi M-R, Zarafshan H, Khaleghi A, Ahmadi N, Hooshyari Z, Mostafavi S-A, et al. Prevalence of ADHD and Its Comorbidities in a Population-Based Sample. Journal of Attention Disorders. 2019:1087054719886372.

9. Veenman B, Luman M, Hoeksma J, Pieterse K, Oosterlaan J. A randomized effectiveness trial of a behavioral teacher program targeting ADHD symptoms. Journal of attention disorders. 2019;23(3):293304.

10. Llanes E, Blacher J, Stavropoulos K, Eisenhower A. Parent and teacher reports of comorbid anxiety and ADHD symptoms in children with ASD. Journal of autism and developmental disorders. 2018:1-12.

11. Pitula $C E$, DePasquale $C E$, Mliner SB, Gunnar MR. Peer problems among postinstitutionalized, internationally adopted children: Relations to hypocortisolism, parenting quality, and ADHD symptoms. 
Child development. 2019;90(3):e339-e55.

12. Miller M, losif A-M, Young GS, Hill MM, Ozonoff S. Early detection of ADHD: Insights from infant siblings of children with autism. Journal of Clinical Child \& Adolescent Psychology. 2018;47(5):737-44.

13. Hosseinnia M, Mazaheri MA, Heidari Z. Knowledge, attitude, and behavior of elementary teachers regarding attention deficit hyperactivity disorder. Journal of Education and Health Promotion. 2020;9(1):120.

14. Khalil Al, Alshareef FA, Alshumrani HG. Knowledge, Attitude, and Behavioural Practice of Elementary Teacher of ADHD Children: Impact of an Educational Intervention. American Journal of Nursing. 2019;8(6):329-41.

15. Lasisi D, Ani C, Lasebikan V, Sheikh L, Omigbodun O. Effect of attention-deficit-hyperactivity-disorder training program on the knowledge and attitudes of primary school teachers in Kaduna, North West Nigeria. Child and adolescent psychiatry and mental health. 2017;11(1):15.

16. Khademi M, Rajeziesfahani S, Noorbakhsh S, Panaghi L, Davari-Ashtiani R, Razjouyan K, et al. Knowledge and attitude of primary school teachers in Tehran/Iran towards ADHD and SLD. Global Journal of Health Science. 2016;8(12):141-9.

17. Shehata A, Mahrous E, Farrag E, Hassan Z. Effectiveness of structured teaching program on knowledge, attitude, and management strategies among teachers of primary school toward children with attention deficit hyperactivity disorder. IOSR Journal of Nursing and Health Science. 2016;5(6):29-37.

18. Sciutto MJ, Terjesen MD, Kučerová A, Michalová Z, Schmiedeler S, Antonopoulou K, et al. Cross-national comparisons of teachers' knowledge and misconceptions of ADHD. International Perspectives in Psychology: Research, Practice, Consultation. 2016;5(1):34.

19. Latouche AP, Gascoigne M. In-service training for increasing teachers' ADHD knowledge and selfefficacy. Journal of attention disorders. 2017;23(3):270-81.

20. Amiri S, Noorazar SG, Fakhari A, Darounkolaee AG, Gharehgoz AB. Knowledge and attitudes of preschool teachers regarding attention deficit hyperactivity disorder. Iranian Journal of Pediatrics. 2017;27(1).

21. Fabiano GA, Pyle K. Best practices in school mental health for attention-deficit/hyperactivity disorder: a framework for intervention. School Mental Health. 2019;11(1):72-91.

22. Latouche AP, Gascoigne M. In-service training for increasing teachers' ADHD knowledge and selfefficacy. Journal of attention disorders. 2019;23(3):270-81.

23. Barkley RA. Classroom accommodations for children with ADHD. The ADHD Report. 2008;16(4):7-10.

24. Park SJ, Park WJ. Development and Effects of an Instructional Coaching Program Regarding Children with Attention Deficit Hyperactivity Disorder for Elementary School Teachers. Journal of Korean Academy of Nursing. 2017;47(3):305-18. 